\title{
Activating JAK3 Gene Mutation
}

National Cancer Institute

\section{Source}

National Cancer Institute. Activating /AK3 Gene Mutation. NCI Thesaurus. Code C157593.

A change in the nucleotide sequence of the JAK3 gene that that results in constitutive activation of both tyrosine-protein kinase JAK3 and its downstream signaling pathways. 